\title{
INFLUENCE OF PORCELAIN FIRING AND CORE THICKNESS ON MARGINAL GAP OF CAD/CAM AND PRESSABLE ALL-CERAMIC CROWNS (IN-VITRO STUDY)
}

\author{
Mohamed Fattouh Abdullah * and Laila M.M. Kenawi **
}

\begin{abstract}
Statement of Problem: Marginal gap is important for the long-term success of all-ceramic restorations, the marginal accuracy of different manufacturing techniques and core thicknesses must be considered.

Purpose: This in-vitro study compared marginal gap of CAD/CAM and heat-pressed ceramic cores with different thicknesses before and after veneering porcelain application.

Materials and Methods: A standard stainless-steel die was prepared. Sixty resin dies were duplicated. Samples were divided into two groups, Group I: samples were fabricated by CAD/ CAM, Group II: samples were fabricated by heat pressing. Each group was divided into three subgroups: Subgroup 1: cores of $0.3 \mathrm{~mm}$. thickness, Subgroup 2: cores of $0.5 \mathrm{~mm}$. thickness, Subgroup 3: full contoured (monolithic) crowns were manufactured by characterization technique. Marginal gap was measured at core stage (pre-firing) and after veneering porcelain firings (postfiring) using a microscope at 40X magnification. Data were statistically analyzed.
\end{abstract}

Results: Marginal gaps of CAD/CAM samples in all subgroups were higher than pressable $(\mathrm{P}<0.05)$. A significant increase in the marginal gap was observed after porcelain firing. Full contour crowns recorded the lowest marginal gap $(58.54 \pm 9.1,32.76 \pm 8.5)$ followed by $0.5 \mathrm{~mm}$. thickness $(66.7 \pm 8.4,40.06 \pm 4.1)$ while $0.3 \mathrm{~mm}$. thickness recorded the highest value $(81.14 \pm 12.3$, 47.96 \pm 7.15). Significant difference was observed in pre-firing and post firing gap values in $0.3 \mathrm{~mm}$. thickness $(\mathrm{P}=0.001)$, while in $0.5 \mathrm{~mm}$. thickness and full contour there were no significant difference $(\mathrm{P}=0.657$ and 0.88 respectively). No statistically significant difference was found in mean marginal gap between $0.5 \mathrm{~mm}$. and $0.3 \mathrm{~mm}$. at both pre-firing and post-firing.

Conclusion: Marginal gap values observed were all within the clinically acceptable range (120 $\mu \mathrm{m})$. Marginal gap increased after porcelain firing in both groups. For esthetic reasons especially in the anterior teeth, $0.3 \mathrm{~mm}$ core thickness can be used instead of $0.5 \mathrm{~mm}$.

KEYWORDS: CAD / CAM , Pressable ceramic, Porcelain firing, Marginal gap, Core thickness.

* Associate Professor, Fixed Prosthodontics Department, Faculty of Dentistry, Cairo University, Giza, Egypt.

** Associate Professor, Endodontic Department, Faculty of Dentistry, Cairo University, Giza, Egypt. 


\section{INTRODUCTION}

Nowadays, increasing esthetic demand had led to popularity of ceramic restoration systems, different techniques were used to fabricate ceramic crowns either machinably or manually ${ }^{(1)}$. Computer-aided design/computer-aided manufacturing $(\mathrm{CAD} / \mathrm{CAM})$ is the least technique that depends on the skills of the lab technician ${ }^{(2)}$. Cercon is CAD CAM machine that fabricates copings, frameworks and full anatomical (monolithic) all-ceramic restorations made of Y-TZP zirconia (yttrium-stabilized tetragonal zirconia polycrystals) providing a highly esthetic restorations ${ }^{(3)}$. While Pressable technique uses lost wax method to fabricate ceramic restorations, IPS E-max Press is a highly esthetic lithium disilicate glass-ceramic manufactured by Press technique, it is used to fabricate inlays, onlays, crowns and three units FPD in premolar regions (4). Natural esthetic appearance of restorations can be achieved by two different techniques; a characterization technique or a layering technique. In the latter technique, copings are manufactured, and feldspathic porcelain is layered over to obtain the definitive translucency and shape ${ }^{(5)}$. From clinical point of view, the esthetic parameters, mechanical properties and marginal fit are very important for longevity of ceramic restorations. Excellent marginal fit of crowns will decrease plaque accumulation and occurrences of periodontal diseases leading to clinical success ${ }^{(6)}$.An acceptable marginal gap for ceramic restorations should be less than $120 \mu \mathrm{m}^{(7)}$, whereas marginal fit more than $120 \mu$ m may lead to plaque accumulation, solubility of luting cements, caries, pulpitis and periodontitis ${ }^{(8)}$.Monolithic restorations have high fracture and flexural strengths but, manufacturers recommend applying this material in reduced thicknesses to achieve better translucency and a better esthetic result ${ }^{(9)}$. Researchers suggested that minimum thickness of walls are 0.3 to $0.5 \mathrm{~mm}$ and only $0.5 \mathrm{~mm}$ occlusal thickness for monolithic restorations ${ }^{(10,11)}$. Crowns of reduced thickness do not require heavy preparation, and consequently more tooth structure can be conserved, especially in critical areas when there is not enough occlusal space and in preparation on the root surface ${ }^{(12-13)}$. Great controversies were showed on the effects of the ceramic materials and core thicknesses on marginal fit. Several studies showed that porcelain firing didn't affect marginal fit of ceramic restorations ${ }^{(14,15)}$. In contrast, others reported marked increase of marginal gap after firing of porcelain ${ }^{(16,17)}$. Therefore, the aim of our study was to asses in-vitro marginal gaps of ceramic samples manufactured by $\mathrm{CAD} / \mathrm{CAM}$ and pressable systems with different core thicknesses and to compare them to full anatomical monolithic crowns. The null hypothesis was that there will be no difference in the marginal gap between the two tested ceramics as well as tested thicknesses before and after veneering porcelain firing.

\section{MATERIALS AND METHOD}

An engineering lathe (Automatic feedback latheBV20B-L Bengu Dome Siticmaxhime tool, China) was used to prepare a standardized stainless-steel die (Fig. 1), to simulate a prepared lower first molar (7 mm. in height, $1 \mathrm{~mm}$. finish line, 5 degrees axial convergence and with occlusal notch to prevent crown rotation) ${ }^{(18)}$. According to previous studies ${ }^{(7,10,16)}$, ten specimens in each subgroup representing an $80 \%$ power to detect a difference between means of $47.9(\mu \mathrm{m})$, sample size was calculated using power analysis software $\left(G^{*}\right.$ Power). Sixty impressions of the die were made using polyether material (Impregum Penta; 3M ESPE,USA). The impressions were poured using self-cure acrylic resin (Table Top Epoxy Resin-clear crystal-USA) using the manufacturer's recommended liquid/ powder ratio to produce resin dies, these dies will be used for measurements of the marginal gaps. The resin dies were divided into two equal groups (thirty samples in each group), Group I: crowns were fabricated using Cercon CAD/CAM machine (Degudent GmbH, Hanau, Germany), Group II: 


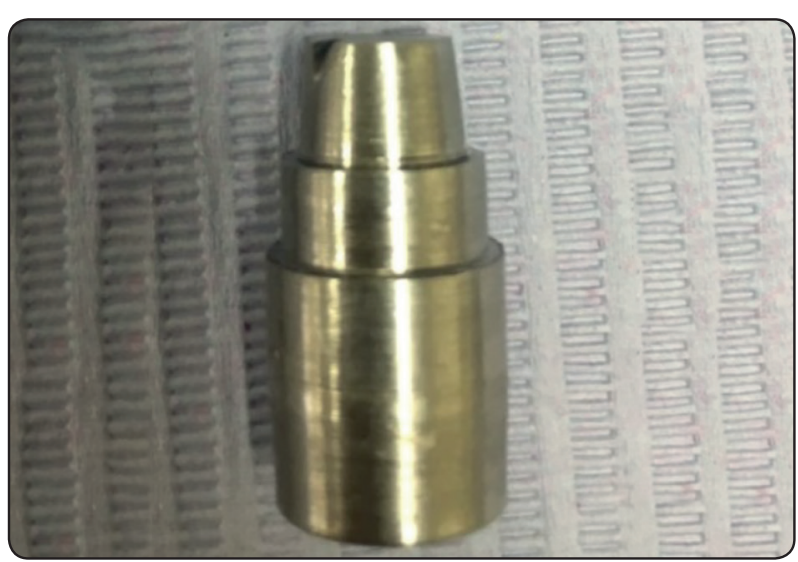

Fig. (1) Demonstrate the Standard Metallic die

crowns were fabricated by Pressable technique using IPS E-max Press( Ivoclar-Vivadent, Schaan, Liechtenstein) . Each group was further divided into three subgroups: Subgroup 1: cores were manufactured of $0.3 \mathrm{~mm}$ thickness, Subgroup 2: cores were manufactured of $0.5 \mathrm{~mm}$. thickness. Subgroup 3: full anatomical contoured (monolithic) crowns were manufactured by characterization TABLE (1) Factorial design of the study. technique where axial wall thickness is $1 \mathrm{~mm}$. (Table: 1). In subgroups 1 and 2 cores were veneered by application of feldspathic porcelain, a silicone index (Stomaflex Putty, Spofa Dental; Markova, Czech Republic) was made for monolithic crown to aid in standardization of veneering layers' thickness .Then the three subgroups underwent glaze cycle.

Manufacturing of restorations in group I (CAD/CAM) using Cercon machine: (Fig.2) Working resin dies were sprayed by Cercon scan spray (Degudent $\mathrm{GmbH}$, Hanau, Germany), to be easily scanned by Cercon laser scanner (Cercon EYE, Degudent; Germany). For subgroup 1: cores were designed using a CAD software (Cercon ART, Degudent; Germany.). The virtual cement thickness was set as $30 \mu \mathrm{m}$, Spacer coverage was $90 \%$ spacer coverage, $0.5 \mathrm{~mm}$ occlusal to finish line as suggested by the manufacturer, axial walls of the cores were set to $0.3 \mathrm{~mm}$. thickness, for subgroup 2: Cercon ART were designed as subgroup 1 but core thickness was set to be $0.5 \mathrm{~mm}$. similarly subgroup

\begin{tabular}{|c|c|c|c|c|c|}
\hline \multicolumn{3}{|c|}{$\begin{array}{c}\text { CAD/CAM (Cercon) crowns } \\
\text { (30 samples) }\end{array}$} & \multicolumn{3}{c|}{$\begin{array}{c}\text { Pressable (IPS E-max Press) crowns } \\
\text { (30 samples) }\end{array}$} \\
\hline $\begin{array}{c}\text { Core } 0.3 \mathrm{~mm} . \\
(10 \mathrm{samples})\end{array}$ & $\begin{array}{c}\text { Core } 0.5 \mathrm{~mm} . \\
(10 \text { samples })\end{array}$ & $\begin{array}{c}\text { Full contour } \\
(10 \text { samples })\end{array}$ & $\begin{array}{c}\text { Core } 0.3 \mathrm{~mm} . \\
(10 \mathrm{samples})\end{array}$ & $\begin{array}{c}\text { Core 0.5 mm. (10 } \\
\text { samples })\end{array}$ & $\begin{array}{c}\text { Full contour } \\
(10 \text { samples })\end{array}$ \\
\hline \multicolumn{3}{|c|}{ Total number of samples $=60$} \\
\hline
\end{tabular}

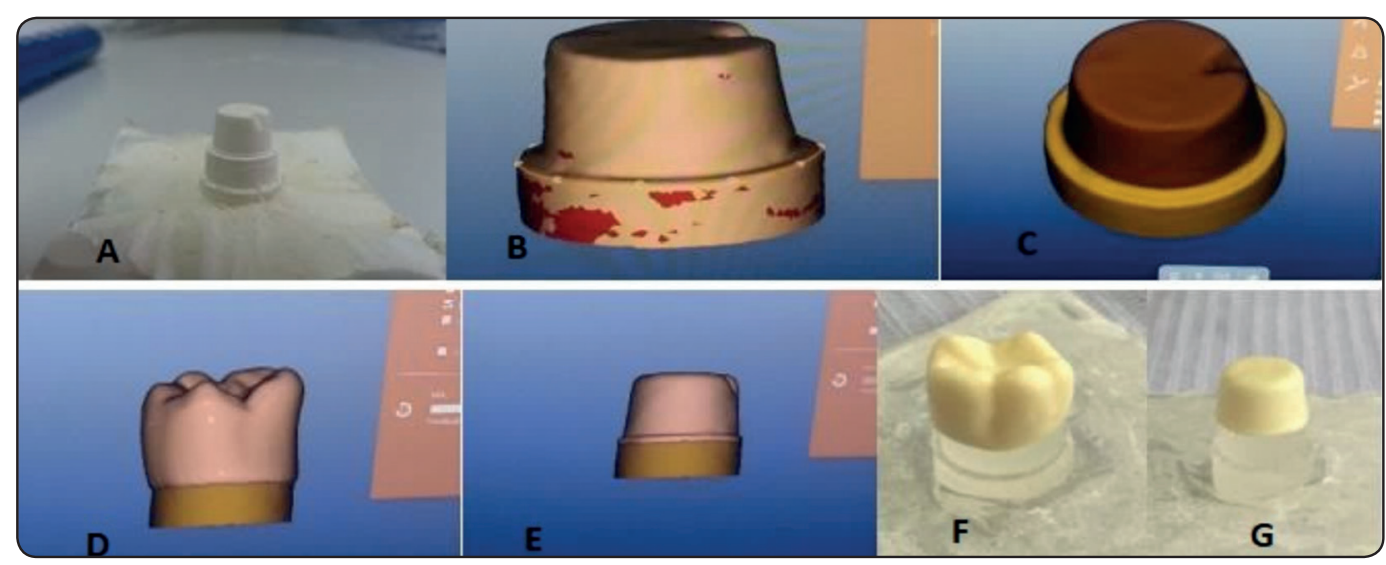

Fig. (2) Various steps of CAD/CAM Cercon crowns and copings fabrication A: resin die sprayed with Cercon scan spray, B: Die scanning, C: Virtual cement application, D: designed full contour crown, E: Designed coping, F: Milled full contour crown and coping, G: Milled coping 
3 were designed by Cercon ART the restoration was full contour crown with axial wall thickness of $1 \mathrm{~mm}$. Designed restorations were sent to the milling machine (Cercon brain, Degudent; Germany) using flash memory card, then zirconia discs (Cercon base \#47; DENSPLY Sirona Inc., USA.) were milled using a CAM system in Cercon Brain. Cercon brain gives partially sintered ceramic cores and crowns with an enlargement factor (approximately $18 \%$ linear enlargement) to compensate for future sintering shrinkage. The samples were cut off the milled blank and were further sintered in a special furnace (Cercon Heat, Degudent $\mathrm{GmbH}$, Hanau, Germany) at $1350^{\circ} \mathrm{C}$ for 6 hours ${ }^{(19)}$. All cores were sandblasted with $50 \mu \mathrm{m}$ alumina particles, ultrasonically and then dried. Veneering porcelain (Cercon Ceram kiss, dentin DB4, DENSPLY, Germany) was built-up incrementally to restore the final anatomical shape of the crown using the silicon index, they underwent two dentin firing cycles at $830^{\circ} \mathrm{C}$ then, $820^{\circ} \mathrm{C}$ under vacuum. Finally, the glaze (Cercon Ceram kiss, Glaze, Hanau, Germany and Ducera Liquid Stain improved, Germany) was applied and fired with the vacuum off at $810^{\circ} \mathrm{C}$ according to manufacturer's recommendations.

\section{Manufacturing of restorations in group II using Pressable technique (IPS E-max Press):}

The Previous steps of designing restorations were repeated using Cercon Art to design $0.3 \mathrm{~mm}$, $0.5 \mathrm{~mm}$ cores and $1 \mathrm{~mm}$. full anatomical crowns in subgroups 1,2 and 3 respectively. However, during CAM process Cercon resin discs (Cercon base B1 PMMA disc 25, Dentsply Sirona Inc., USA) were used in Cercon Brain to produce standardized resin patterns. All resin samples were invested using press investment (IPS PressVest, Ivoclar-Vivadent, Schaan, Liechtenstein), powder and liquid were mixed then poured inside the silicone ring and allowed to set (Fig.3). The base was pushed out carefully from IPS Silicone ring, the ring was burned out by electrical furnace at $850^{\circ} \mathrm{C}$ for eighty minutes. A ceramic ingot (IPS E.max Press
LT, Ivoclar Vivadent, Schaan, Liechtenstein) was injected into opening of the investment ring, heat pressing was applied in a press furnace (EP 3000, Ivoclar Vivadent, Schaan, Liechtenstein) at $850^{\circ} \mathrm{C}$ for eighteen minutes using plunger. After the press cycle, the investment ring was allowed to cool,

Then divestment of the restorations were carried using sandblast machine with $50 \mu \mathrm{m}$ alumina particles and a pressure of 4 bars to remove of the investment, the inner silicon dioxide film and any impurities. Sprues were separated from pressed cores and crowns using diamond cutting wheel saw. All samples are immersed in IPS E.max Press invex liquid (Ivoclar Vivadent, Schaan, Liechtenstein) for 20 minutes then washed in distilled water and dried. Followed by application of veneering porcelain (IPS Empress universal shade paste A-D, Ivoclar Vivadent, Schaan, Liechtenstein) for subgroups 1 and 2. Glaze (IPS e.max Ceram Glaze Liquid, Ivoclar Vivadent, Schaan, Liechtenstein) was applied and fired in porcelain furnace (Programat P.200, Ivoclar- Vivadent, Schaan, Liechtenstein) for the three subgroups. Any defective cores or crowns in both groups were excluded from study.

\section{Measurement of marginal gap}

Marginal gap was measured in the cores and full anatomical crowns before firing of the veneering porcelain (Pre-firing measurements) and after firing and glazing (Post-firing measurements) Measurements were carried using light microscope (Leica M320 F12, Leica Microsystems Inc., Wetzlar, Germany) with a built-in camera connected with an IBM compatible personal computer using a magnification of $40 \mathrm{X}$. Four fixed marks were drawn on resin dies (mid facial, mid mesial, mid distal, mid lingual) to ensure repetition of location during measurement after porcelain firing, three readings were taken at each surface of the samples giving twelve measurements per crown (Fig. 4). The collected data were statistically analyzed using SPSS version 22 (IBM Inc., USA). Statistically significant difference was obtained at P-value less than 0.05 . 


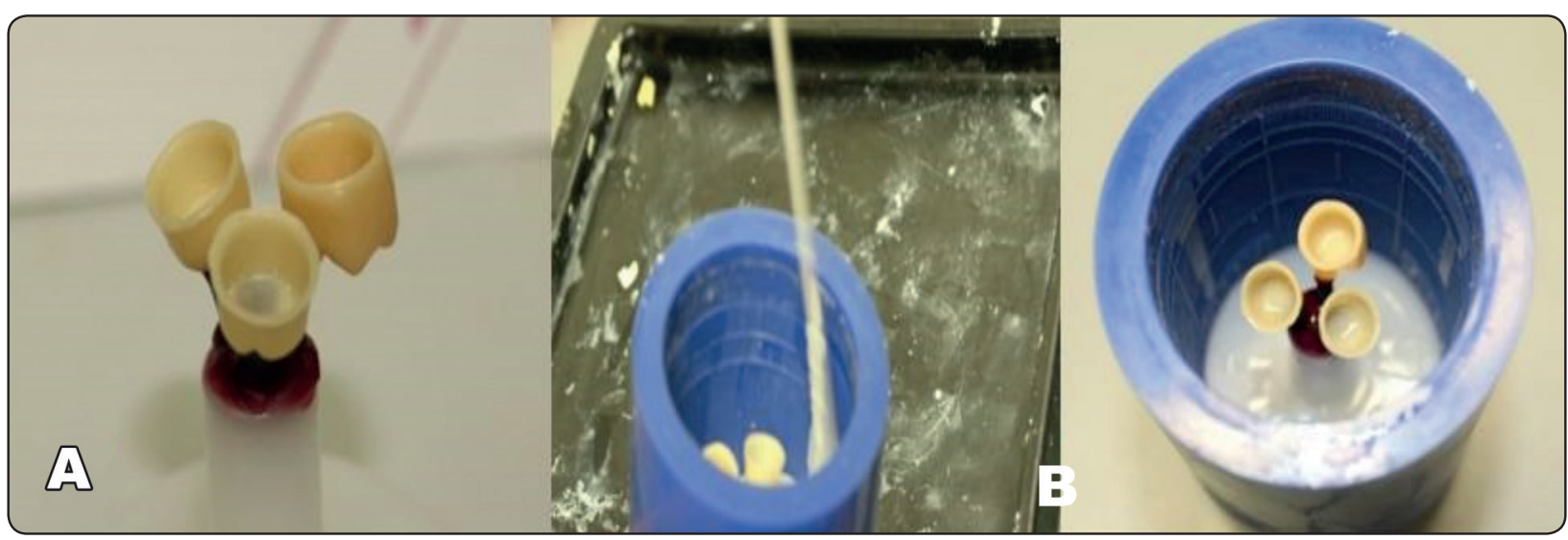

Fig. (3) A: Spruing of Pressable cores and crowns, B: Investing.

\section{RESULTS}

Table 2, 3 and figure 5 show the means and standard deviations of the marginal gaps of $\mathrm{CAD} /$ CAM and Pressable groups with different core thicknesses at pre-firing and post-firing stages respectively. There were statistically significant differences in the mean marginal gaps between $\mathrm{CAD} / \mathrm{CAM}$ and Pressable samples at pre-firing and post-firing porcelain stages. Also, there were significant differences in mean marginal gap between pre-firing and post-firing (Table 4). Regarding the core thicknesses, in each studied group; the full contour recorded the lowest marginal gap mean value followed by $0.5 \mathrm{~mm}$. thickness while the $0.3 \mathrm{~mm}$. core recorded the highest value. Regarding before and after porcelain firing score of the marginal gaps,non-significant differences were recorded between the studied subgroups as indicated by one-way ANOVA test before and after porcelain firing (table 5).Dependent-samples $\mathrm{T}$ test was then employed to find out the significant difference for each core thickness alone during pre-firing and post-firing stages and revealed that in subgroup1 $(0.3 \mathrm{~mm}$.) there was a significant difference, while in subgroups $2(0.5 \mathrm{~mm}$.) and 3 (full contour) there were no significant difference. There was no statistically significant difference in mean marginal gap between $0.5 \mathrm{~mm}$. and $0.3 \mathrm{~mm}$. at both pre-firing and post-firing (table 5).
TABLE (2) Mean marginal gap $(\mu \mathrm{m})$ and SD for ceramic samples before porcelain firing (pre-firing)

\begin{tabular}{|c|c|c|c|}
\hline $\begin{array}{c}\text { Core thickness } \\
(\mathrm{mm} .)\end{array}$ & CAD/CAM & Pressable & P-value \\
\hline 0.3 & $78.2 \pm 11.69$ & $44.8 \pm 4.54$ & $\mathbf{0 . 0 0 2} *$ \\
\hline 0.5 & $65.6 \pm 7.8$ & $39 \pm 4.3$ & $\mathbf{0 . 0 0 1 *}$ \\
\hline Full & $58.46 \pm 9.15$ & $32.32 \pm 8.47$ & $\mathbf{0 . 0 0 2} *$ \\
\hline P-value & $\mathbf{0 . 0 2 2} *$ & $\mathbf{0 . 0 2 3} *$ & \\
\hline
\end{tabular}

TABLE (3) Mean marginal gap $(\mu \mathrm{m})$ and SD for ceramic samples after porcelain firing (post-firing)

\begin{tabular}{|c|c|c|c|}
\hline $\begin{array}{c}\text { Core thickness } \\
(\mathrm{mm} .)\end{array}$ & CAD/CAM & Pressable & P-value \\
\hline 0.3 & $81.14 \pm 12.3$ & $47.96 \pm 7.15$ & $\mathbf{0 . 0 0 2 *}$ \\
\hline 0.5 & $66.7 \pm 8.4$ & $40.06 \pm 4.1$ & $\mathbf{0 . 0 0 1 *}$ \\
\hline Full & $58.54 \pm 9.1$ & $32.76 \pm 8.5$ & $\mathbf{0 . 0 0 2} *$ \\
\hline P-value & $\mathbf{0 . 0 1 5 *}$ & $\mathbf{0 . 0 1 3} *$ & \\
\hline
\end{tabular}

TABLE (4) Mean marginal gap $(\mu \mathrm{m})$ and SD for tested groups

\begin{tabular}{|c|c|c|c|}
\hline Ceramic type & $\begin{array}{c}\text { Pre- Porc. } \\
\text { firing }\end{array}$ & $\begin{array}{c}\text { Post- Porc. } \\
\text { firing }\end{array}$ & P-value \\
\hline CAD/CAM & $67.4 \pm 12.3$ & $68.75 \pm 13.7$ & $\mathbf{0 . 0 2} *$ \\
\hline Pressable & $38.7 \pm 7.7$ & $39.7 \pm 9.2$ & $\mathbf{0 . 1 9}$ \\
\hline P-value & $\mathbf{0 . 0 0 1 *}$ & $\mathbf{0 . 0 0 1} *$ & \\
\hline
\end{tabular}


TABLE (5) Mean marginal gap $(\mu \mathrm{m})$ and SD for different tested thicknesses

\begin{tabular}{|c|c|c|c|}
\hline $\begin{array}{c}\text { Core thickness } \\
(\mathrm{mm} .)\end{array}$ & $\begin{array}{c}\text { Pre- Porc. } \\
\text { firing }\end{array}$ & $\begin{array}{c}\text { Post- Porc. } \\
\text { firing }\end{array}$ & P-value \\
\hline 0.3 & $61.5 \pm 19.5^{\text {a }}$ & $64.55 \pm 19.9^{\text {b }}$ & $\mathbf{0 . 0 0 1}^{*}$ \\
\hline 0.5 & $52.3 \pm 15.2^{\text {a }}$ & $52.7 \pm 16.1^{\mathbf{b}}$ & $\mathbf{0 . 6 5 7}$ \\
\hline Full & $45.39 \pm 16.09$ & $45.45 \pm 16.2$ & $\mathbf{0 . 8 8}$ \\
\hline P-value & $\mathbf{0 . 1 2 5}$ & $\mathbf{0 . 0 6 5}$ & \\
\hline
\end{tabular}

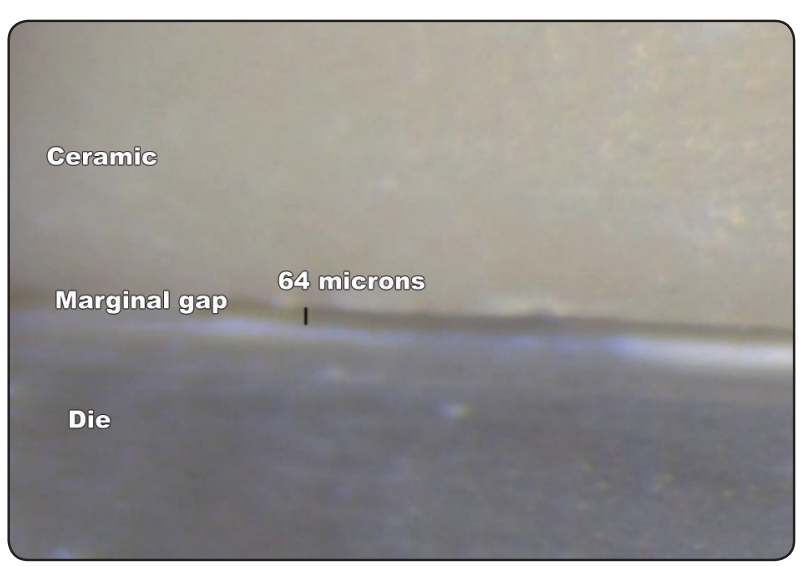

Fig. (4) Marginal Gap measurement with Microscope.

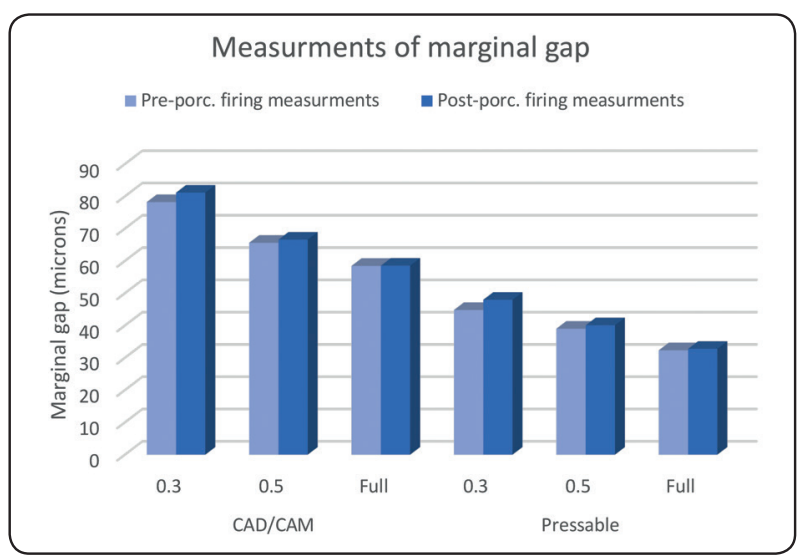

Fig. (5) Column chart of mean marginal gap of tested samples.

\section{DISCUSSION}

In the present study, a standard stainless-steel die was used. Many studies used metal ${ }^{(20)}$ or acrylic resin ${ }^{(21)}$ dies to measure the marginal fit. Sixty epoxy resin dies were duplicated from a metallic die to be used as abutments and ensure accurate duplication of the preparation and abrasion resistance during manufacturing and testing. As die spacer is a major factor in fitness of the crown as confirmed by Weaver et al ${ }^{(22)}$, standard die spacer was selected on Cercon machine to be $30 \mu \mathrm{m}$.

Marginal gaps have been evaluated using many methods as clinical examination, impression replica technique, cross section view and direct viewing ${ }^{(23,24)}$. However, marginal gap of the non-sectioned samples is usually examined using direct microscopic view of the interface. In our study, marginal gaps of samples were measured using light microscope in the vertical plane using four different points for each specimen. It was reported in a previous study that there was no significant difference between the accuracy of light microscopy and scanning electron microscope measurements techniques during measuring marginal discrepancies ${ }^{(25)}$. Our results showed that there were significant differences between the marginal gap of the studied groups. Pressed group showed mean marginal gap of 39.48 $\mu \mathrm{m}$ that was smaller than that of CAD/CAM group $(68.09 \mu \mathrm{m})$. This may be attributed to different manufacturing techniques, pressable coping exhibited less distortion in comparison to CAD/ $\mathrm{CAM}$ as $\mathrm{CAD} / \mathrm{CAM}$ process had more complex procedures with computer program computation (26). Moreover, CAD/CAM technology had some disadvantages regarding software limitations during designing of the restorations as well as hardware limitations with scanning apparatus and milling units. Also, aging of machine cutting tools and their different sizes may dramatically affect the marginal accuracy ${ }^{(27)}$. Our results are in agreement with the results of other studies ${ }^{(28-30)}$ that showed higher marginal accuracy in pressable restorations than CAD/CAM. But, Guess et al ${ }^{(27)}$ reported that there were no differences between marginal fit of onlays manufactured by CEREC CAD/CAM and pressed techniques. Furthermore, $\mathrm{Ng}$ et al (31) found that LAVA CAD/CAM crowns have better marginal fit than pressed crowns. These variations in results might be due to different CAD/CAM 
machines, different sorts of microscope with various magnifications in each research. Marginal gaps measured in this study in different subgroups core thicknesses are acceptable in the molecular and bacterial level (less than $120 \mu \mathrm{m}$ ) ${ }^{(7)}$. McLean and Von Fraunhofer studied-over 5 years periodone thousand ceramic restorations, reporting that $120 \mu \mathrm{m}$ represented the maximum accepted marginal gap ${ }^{(32)}$. In our study, there were statistically significant differences before and after firing and glazing of the porcelain, this is in agreement with several studies ${ }^{(33-37)}$ which showed increase in the marginal gap after porcelain application. The core distortion occurring during porcelain firing cycle might be due to non-uniform porcelain mass, where porcelain bulk affects the firing shrinkage, thus increasing porcelain bulk labially and lingually may lead to greater marginal gap. The distortion of the cores during porcelain firing cycles may increase the marginal gap affecting the success of the restoration (33). The marginal gap of samples in subgroups 2 and 3 of both groups showed a non- significant change (table 5) before and after the firing of the veneering porcelain indicating that sintering of $\mathrm{CAD} / \mathrm{CAM}$ samples at $1350^{\circ} \mathrm{C}$ will convert the partially-sintered cores to full stabilized zirconia with tetragonal polycrystals, and then porcelain veneering at $850^{\circ} \mathrm{C}$ did not affect the marginal gap , but the statistically significant difference between pre-firing and postfiring in subgroups 1 indicated that using a thin core of $0.3 \mathrm{~mm}$. thickness may cause higher marginal gap after porcelain application and glazing. This study found non significant difference in mean marginal gap between $0.5 \mathrm{~mm}$. and $0.3 \mathrm{~mm}$. core thicknesses. So, in critical anterior areas where esthetic is important, core thickness can be decreased safely from $0.5 \mathrm{~mm}$. to $0.3 \mathrm{~mm}$. Jalali ${ }^{(10)}$ et al. compared the effect of chamfer and radial shoulder on marginal gap of ceramic restorations, reporting that gap in radial shoulder groups was higher than in chamfer one, their study differs from our that they used only one core thickness of $0.5 \mathrm{~mm}$. while we studied three different thicknesses. Our results are in contrast with that reported by Dolev et al ${ }^{(38)}$ who compared fit of ceramic crowns with different finish lines, before and after porcelain firing and glazing. These differences may be that their crowns were cemented to simulate clinical conditions, and the use of finger pressure in the cementation process. Weaver et al (26) showed that seating force by fingers was $78.5 \mathrm{~N}$, while cotton rolls exerted a force of $137 \mathrm{~N}$. during cementation. This study has some limitations. Crowns were fabricated without an impression; the samples were not cemented and there was no artificial aging process. In-vitro mechanical loading and thermal cycling are generally used to simulate in-vivo conditions. Hung et al ${ }^{(39)}$ reported increase in marginal gap after thermal cycling of crowns. However, Beschnidt and Strub ${ }^{(23)}$ showed that aging procedure didn't affect marginal fit of different all-ceramic systems. Another limitation is that this study examined the marginal gap values of posterior single crowns with standard reduction. Also, the using of bridges may give different marginal gap measurments due to different geometrical forms.

\section{CONCLUSIONS}

The following conclusions can be drawn-within the limitations of this study:

- Marginal gap values observed were all within the clinically acceptable range $(120 \mu \mathrm{m})$.

- Marginal gap significantly increased after porcelain firing in both groups.

- No Significant difference in pre-firing and post firing gap values for full contour and $0.5 \mathrm{~mm}$. thickness while there was significant difference in $0.3 \mathrm{~mm}$. thickness core.

- For esthetic reasons especially in the anterior teeth, $0.3 \mathrm{~mm}$. core thickness can be used instead of $0.5 \mathrm{~mm}$.

Further investigation is necessary to evaluate the effect of cementation, the aging process, different tooth preparation designs, fixed partial dentures on the margin accuracy. 


\section{Conflict of interest}

No conflicts of interest and No funding was received for this study that could have influenced its results.

\section{REFERENCES}

1. Conrad HJ, Seong WJ, Pesun IJ. Current ceramic materials and systems with clinical recommendations: a systematic review. J Prosthet Dent. 2007 Nov;98(5):389-404.

2. Strub JR, Rekow ED, Witkowski S. Computer-aided design and fabrication of dental restorations: current systems and future possibilities. J Am Dent Assoc. 2006 Sep;137(9):1289-96.

3. Denry I, Kelly JR. State of the art of zirconia for dental applications. Dent Mater. 2008 Mar;24(3):299-307.

4. Scientific documentation of E-max Press Available on the internet at: https://www.ivoclarvivadent.com/.../media/.../ IPS+Empress+System+-+Dental +Labs.

5. Komine F, Shiratsuchi H, Kakehashi Y, Matsumura H. Influence of porcelain-firing procedures on the marginal distortion of electroformed metal-ceramic restorations. Quintessence Int. 2007;38:583-8.

6. White SN, Sorensen JA, Kang SK, Caputo AA. Microleakage of a new crown and fixed partial denture luting agent $\mathrm{J}$. Prosthet. Dent. 1992; 67:156-161.

7. De Paula Silveira AC, Chaves SB, Hilgert LA, Ribeiro AP. Marginal and internal fit of CAD-CAM-fabricated composite resin and ceramic crowns scanned by 2 intraoral cameras. J Prosthet Dent. 2017 Mar;117(3):386-392.

8. Contrepois M, Soenen A, Bartala M, Laviole O. Marginal adaptation of ceramic crowns: a systematic review. J Prosthet Dent 2013; 110:447-54-10.

9. Øilo M, Kvam K, Gjerdet NR. Load at fracture of monolithic and bilayered zirconia crowns with and without a cervical zirconia collar. J Prosthet Dent. 2016 May;115(5):630-6.

10. Jalali H, Sadighpour L, Miri A, Shamshiri AR. Comparison of Marginal Fit and Fracture Strength of a CAD/CAM Zirconia Crown with Two Preparation Designs. J Dent (Tehran). 2015 Dec;12(12):874-81.

11. Hansen TL, Schriwer C, Øilo M, Gjengedal H. Monolithic zirconia crowns in the aesthetic zone in heavy grinders with severe tooth wear - An observational case-series. J Dent. 2018 May; 72:14-20.
12. Lan TH, Pan CY, Liu PH, Chou MMC. Fracture Resistance of Monolithic Zirconia Crowns in Implant Prostheses in Patients with Bruxism. Materials (Basel). 2019 May 17;12(10):1623.

13. Øilo, Marit \& Schriwer, Christian \& Flinn, Brian \& Gjerdet, Nils Roar. Monolithic zirconia crowns - wall thickness, surface treatment and load at fracture. Biomaterial Investigations in Dentistry. 2019 Dec.; 6(1):13-22

14. Vigolo P, Fonzi F. An in vitro evaluation of fit of zirconium-oxide-based ceramic four-unit fixed partial dentures, generated with three different CAD/CAM systems, before and after porcelain firing cycles and after glaze cycles. J Prosthodont. 2008 Dec;17(8):621-6.

15. Vult von Steyern P, Ebbesson S, Holmgren J, Haag P, Nilner K. Fracture strength of two oxide ceramic crown systems after cyclic pre-loading and thermocycling. J Oral Rehabil. 2006 Sep;33(9):682-9.

16. Balkaya MC, Cinar A, Pamuk S. Influence of firing cycles on the margin distortion of 3 all-ceramic crown systems. J Prosthet Dent. 2005 Apr;93(4):346-55.

17. Pak HS, Han JS, Lee JB, Kim SH, Yang JH. Influence of porcelain veneering on the marginal fit of Digident and Lava CAD/CAM zirconia ceramic crowns. J Adv Prosthodont. 2010 Jun;2(2):33-8.

18. Shokry TE, Attia M, Mosleh I, Elhosary M, Hamza T, Shen C. Effect of metal selection and porcelain firing on the marginal accuracy of titanium-basedmetal ceramic restorations. J. Prosthet. Dent. 2010; 103:45-52.

19. Cercon smart ceramics- The zirconia all-porcelain system. Cercon art P2 Instructions for use, degudent gmbh, Germany. 2006.

20. Rinke S, Huls A, Jahn L. Marginal accuracy and fracture strength of conventional and copy-milled all-ceramic crowns. Int J Prosthodont 1995; 8:303-10.

21. Pera P, Gilodi S, Bassi F, Carossa S. In vitro marginal adaptation of alumina porcelain ceramic crowns. J Prosthet Dent 1994; 72:585-90.

22. Weaver JD, Johnson GH, Bales DJ. Marginal adaptation of castable ceramic crowns. J Prosthet Dent 1991; 66:747-53.

23. Beschnidt SM, Strub JR. Evaluation of the marginal accuracy of different all-ceramic crown systems after simulation in the artificial mouth. J Oral Rehabil 1999; 26:582-93. 
24. Rastogi A, Kamble V. Comparative analysis of the clinical techniques used in evaluation of marginal accuracy of cast restoration using stereomicroscopy as gold. J Adv Prosthodont 2011; 3:69-75.

25. Groten M, Girthofer S \& Probster L. Marginal fit consistency of copy-milled all-ceramic crowns during fabrication by light and scanning electron microscopic analysis in vitro Journal of Oral Rehabilitation (1997) 24(12) 871-881.

26. Baig MR, Tan KB, Nicholls JI. Evaluation of the marginal fit of a zirconia ceramic computer-aided machined (CAM) crown system. J Prosthet Dent. 2010 Oct;104(4):216-27.

27. Guess PC, Vagkopoulou T, Zhang Y, Wolkewitz M, Strub JR. Marginal and internal fit of heat pressed versus CAD/ CAM fabricated all-ceramic onlays after exposure to thermo-mechanical fatigue. J Dent. 2014 Feb;42(2):199-209.

28. Mously HA, Finkelman M, Zandparsa R, Hirayama H. Marginal and internal adaptation of ceramic crown restorations fabricated with CAD/CAM technology and the heatpress technique. J Prosthet Dent. 2014 Aug;112(2):249-56.

29. Neves FD, Prado CJ, Prudente MS, Carneiro TA, Zancopé $\mathrm{K}$, Davi LR et al. Micro-computed tomography evaluation of marginal fit of lithium disilicate crowns fabricated by using chairside CAD/CAM systems or the heat-pressing technique. J Prosthet Dent. 2014 Nov;112(5):1134-40.

30. Anadioti E, Aquilino SA, Gratton DG, Holloway JA, Denry I, Thomas GW et al. 3D and 2D marginal fit of pressed and CAD/CAM lithium disilicate crowns made from digital and conventional impressions. J Prosthodont. 2014 Dec;23(8):610-7.
31. Ng J, Ruse D, Wyatt C. A comparison of the marginal fit of crowns fabricated with digital and conventional methods. J Prosthet Dent. 2014 Sep;112(3):555-60.

32. McLean JW, Von Fraunhofer JA. The estimation of cement film thickness by an in vivo technique. Br Dent J 1971; 131:107-111.

33. Balkaya MC, Cinar A, Pamuk S. Influence of firing cycles on the margin distortion of 3 all-ceramic crown systems. $\mathrm{J}$ Prosthet Dent 2005; 93: 346-355.

34. Dittmer M, Borchers L, Stiesch M, Kohorst P. Stresses and distortions within zirconia-fixed dental prostheses due to the veneering process. Acta Biomater J 2009; 5:3231-9.

35. Att W, Komine F, Gerds T, Strub JR. Marginal adaptation of three different zirconium dioxide three-unit fixed dental prostheses. J Prosthet Dent 2009; 101:239-47.

36. Kohorst P, Brinkmann H, Dittmer MP, Borchers L, Stiesch M.Influence of the veneering process on the marginal fit of zirconia fixed dental prostheses. J Oral Rehabil 2010; 37:283-91.

37. Farid F, Hajimiragha H, Jelodar R, Mostafavi AS, Nokhbatolfoghahaie. In vitro evaluation of the effect of core thickness and fabrication stages on the marginal accuracy of an all-ceramic system. Dent J 2012;9: 188-94.

38. Dolev E, Bitterman Y, Meirowitz A. Comparison of marginal fit between CAD-CAM and hot-press lithium disilicate crowns. J Prosthet Dent. 2019 Jan;121(1):124-128.

39. Hung SH, Hung KS, Eick JD, Chappell RP. Marginal fit of porcelain-fused to metal and two types of ceramic crown. J Prosthet Dent 1990; 63:26-31. 